\title{
Challenge accepted: Social media as a stereotype change agent
}

\author{
Michelle M. Silva, BA, ${ }^{a}$ and Julie A. Freischlag, MD, FACS, RCSEd(Hon $)^{b}$
}

\footnotetext{
From the ${ }^{\mathrm{a} D a v i s}$ Health Executive Communications Office, Sacramento, Calif; and ${ }^{\mathrm{b}}$ Department of Vascular and Endovascular Surgery, Wake Forest Baptist Medical Center, Winston-Salem, NC. Disclosures: Authors have nothing to disclose with regard to commercial support.

Received for publication June 16, 2017; accepted for publication July 28, 2017.

Address for reprints: Julie A. Freischlag, MD, FACS, RCSEd(Hon), President and CEO, Wake Forest Baptist Medical Center, Medical Center Blvd, Winston-Salem, NC 27157 (E-mail: jfreisch@wakehealth.edu).

J Thorac Cardiovasc Surg 2017;154:1354-5

$0022-5223 / \$ 36.00$

Copyright (C) 2017 by The American Association for Thoracic Surgery

http://dx.doi.org/10.1016/j.jtcvs.2017.07.039
}

It happens often. An airline passenger falls ill, and the flight crew asks over the intercom if a physician is on board to help. In the fall of 2016, a young, black, female physician tried to answer one such request for medical assistance during a flight. She alleges that a flight attendant-who appeared not to believe that a person who was black and female could be a doctor-told her, "We are looking for actual physicians." ${ }^{1}$ Unfortunately, this misperception happens often as well.

In case another person is confused or curious about what actual physicians look like, he or she can Google \#NYerORCoverChallenge to get clear. In the Young Surgeon's Note in this issue of the Journal, authors Antonoff and Stamp ${ }^{2}$ examine how a New Yorker cover illustration quickly turned into a social media movement designed to challenge stereotypes and illuminate the true faces-women and men of all ethnicities and ages — of surgery throughout the world. The cover artist, Malika Favre, said her intent was to "capture that feeling of people watching you lose consciousness,"3 yet it ultimately inspired a hashtag that has boosted consciousness around the threat of bias and stereotypes within the surgical profession.

The \#NYerORCoverChallenge and its well-known predecessor, \#IlookLikeASurgeon, ${ }^{4}$ are important examples of how social media can be leveraged broadly as a cultural change agent. Social media is sparking vital conversations that are challenging sociocultural constructs, evolving historical conceptions, and influencing change in the field of medicine. In their article, Antonoff and Stamp ${ }^{2}$ note how ongoing interactions on Twitter and other social media have fostered great camaraderie and support for many who have felt marginalized in the medical field and also have produced wonderful collaborations and mentorship opportunities, expanding professional networks and connecting people to others outside their institutions. This is especially valuable for women, underrepresented minorities, and those in rural or remote communities who have far fewer role models who look like them-they can connect and engage with those who have the same professional

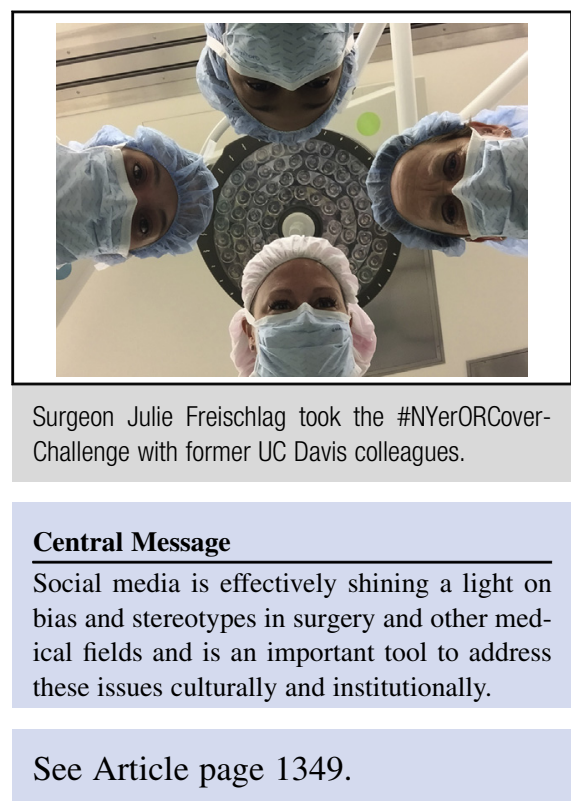

passions and challenges and be inspired through images like those shared as part of the \#NYerORCoverChallenge. (One important note on the beautiful New Yorker cover: Because the artwork was intended to tease the issue's "health, medicine, and the body" theme, rather than to illustrate a social movement, we can forgive the artist for her supermodel-like depiction of female surgeons, with their lovely tapered gloved fingers, perfectly arched brows, and cat-eyed eyeliner, which otherwise subscribes to female beauty myths and stereotypes.)

Antonoff and Stamp ${ }^{2}$ admit that the \#NYerORCoverChallenge and other social media efforts won't "cure all of the cultural issues that permeate society," and they leave us wondering what other tactics they feel might be complementary. Their voices - both as innovators in social media and as female cardiothoracic surgeons - are valuable and can further define change, and we would welcome learning about their continued creative ideas and strategies, particularly around boots-on-the-ground efforts to address inequities in surgery and other medical professions. Not only do we want movements like \#NYerORCoverChallenge to be viral, we also want measurable institutional change around stereotypes and bias to be viral. Let's continue to challenge each other around these issues.

\section{References}

1. Hauser C. Black doctor says Delta flight attendant rejected her; sought 'actual physician.' The New York Times. October 14, 2016. Available at: 
www.nytimes.com/2016/10/15/us/black-doctor-says-delta-flight-attendantbrushed-her-aside-in-search-of-an-actual-physician.html. Accessed June $12,2017$.

2. Antonoff MB, Stamp N. The \#NYerORCoverChallenge: what it means for women in cardiothoracic surgery. J Thorac Cardiovasc Surg. 2017;154: $1349-51$.
3. Mouly F, Bormes G. The New Yorker cover that's being replicated by women surgeons across the world. The New Yorker. April 11, 2017. Available at: www. newyorker.com/culture/rabbit-holes/the-new-yorker-cover-thats-being-replicatedby-women-surgeons-across-the-world. Accessed June 12, 2017.

4. Hughes KA. \#ILookLikeASurgeon goes viral: how it happened. Bull Am Coll Surg. 2015;100:10-6. 